\title{
Cancer patients in COVID-19 outbreak: something more than Suram fortress
}

\author{
Daris Ferrari ${ }^{1}\left[\right.$ [D $\cdot$ Martina Violati ${ }^{1} \cdot$ Carla Codecà $^{1}$
}

Published online: 29 May 2020

○) Springer Science+Business Media, LLC, part of Springer Nature 2020

\section{To the Editor,}

From the beginning of 2020, a sneaky outbreak of a new Coronavirus (SARS-CoV-2) has spread from China to all the world, leaving a trail of ill and dead people, a disease termed COVID-19 [1]. Italy, and Lombardy in particular, was hit hard with almost 15,000 deaths to date. Given the few chances of cure, the most effective bulwarks were the adoption of personal protective equipment and social distancing. In Lombardy, perhaps due to measures taken late, these kind of barriers proved fragile and easily attacked, a sort of legendary Suram fortress, destined to crumble ruinously without a young man sacrifice. The dramatic vision of the virus progressively infecting weaker and older patients has greatly alarmed oncologists, as cancer patients might be the perfect target for SARS-CoV-2. Moreover, concern has extended to healthcare professionals. Thus, the doors of the majority of oncology departments have been closed as soon as possible, sometimes when the horses have bolted.

In order to exclude the virus from entering our Oncology Department, starting from the end of February 2020, strong measures to limit the epidemic were taken. The staff was forced to wear protective masks, gloves, and safety goggles. The access was allowed to patients only, while relatives could accompany them only if very frail and not autonomous, or in case a diagnosis of cancer had to be communicated. Nurses were trained for an appropriate triage process. Temperature was detected in all patients before entry and all were investigated on the recent occurrence of fever, anosmia, cough, and other respiratory symptoms occurring at home. In case of fever or symptoms, a nasopharyngeal swab (NPS) was autonomously performed by a trained nurse and the patients were hospitalized in the Oncology Department only if NPS negative, otherwise they

Daris Ferrari

daris.ferrari@asst-santipaolocarlo.it

1 San Paolo Hospital, Milan, Italy were sent to the Emergency Department with the aim of maintaining the cancer area COVID-19-free. Considering the period from February 26th to April 30th, 630 first and mandatory control visits were performed, and 1360 chemotherapy cycles administered on 405 patients. A total of 1015 patients (and much more relatives) passed through our outpatient ward while the viral storm was raging outside. We identified 30 suspected patients, who underwent NPS, but only two were found positive. While a patient had a mild respiratory syndrome with ground-glass bilateral lung opacities at Computed Tomography (CT) scan, resolving in few days, the other one went through a tumultuous course and died in 2 days. Death was due to the occurrence of severe respiratory failure complicated by diffuse pulmonary thromboembolism. Thoracic CT scan demonstrated the presence of diffuse pulmonary arterial filling defects and typical bilateral pneumonitis, usually accompanying COVID-19, as we know now. Neither hydroxychloroquine nor enoxaparin nor mechanical ventilation was able to limit and arrest the rapid and fatal course in this case.

All healthcare personnel were subjected to NPS. Among 48 doctors, nurses and social health operators, only 2 oncologists with mild symptoms (transient anosmia e low-grade fever) were found to be positive and a quarantine period was arranged for them. It was assumed they contracted the virus during their hard work in the Emergency Department, as a support team.

While the viral weave is slowly subsiding in Italy, now we are trying to focus on our behaviors in order to understand whether our choices made perfect sense. Looking at our numbers, one death out of more than thousand patients and two members of the staff involved, we think our defensive system was indeed something more stable than the fortress of Suram.

COVID-19 may follow an asymptomatic or rapidly fatal course [2]. The outcome depends on the combination between virus attack and host response, triggered by the functional receptor Angiotensin Converting Enzyme 2 
(ACE2), highly expressed on lung epithelial cells. T-cell activation, initiated by antigen presenting cells, flows into the action of $\mathrm{CD}^{+}$and $\mathrm{CD} 8^{+} \mathrm{T}$-cells, the former able to activate B-cells and antibody production, the latter destined to kill viral infected cells [3]. The immune system alterations and the susceptibility to infections typically found in cancer patients have strongly alarmed the world of oncology; hence, many Institutions have developed their own defensive walls. We tried to prevent any complication related to COVID-19 by maintaining a high suspicion index and a series of protective measures. We cannot say accurately how successful was our intervention but, beyond any doubt, the patients themselves made the difference, thanks to their full adherence to our precepts, the stoic calm and patience they showed us every single day and the renewed struggle against cancer they are still fighting.

Author contributions All the Authors equally contributed to the concept and the writing of the paper.

Funding Not applicable.

Data availability Not applicable.

Code availability Not applicable.

\section{Compliance with ethical standards}

Conflict of interest The authors declare they have no conflicts of interest.

Ethical approval Not applicable.

Consent to participate Not applicable.

Consent for publication Not applicable.

\section{References}

1. Zhu N, Zhang D, Wang W, Li X, Yang B, Song J, et al. A novel coronavirus from patients with pneumonia in China, 2019. N Engl J Med. 2020. https://doi.org/10.1056/NEJMoa2001017.

2. Li Q, Guan X, Wu P, Wang X, Zhou L, Tong Y, et al. Early transmission dynamics in Wuhan, China, of novel coronavirus-infected pneumonia. N Engl J Med. 2020. https://doi.org/10.1056/NEJMo a2001316.

3. Yuki K, Fujiogi M, Koutsogiannaki S. COVID-19 pathophysiology: a review. Clin Immunol. 2020. https://doi.org/10.1016/j. clim.2020.108427.

Publisher's Note Springer Nature remains neutral with regard to jurisdictional claims in published maps and institutional affiliations. 